\title{
Assessing the Effects of Social Media on Academic Performance of Female Students at Raya University, Ethiopia
}

\author{
Alexander Haymanot Abrha \\ Lecturer, Department of Civics and Ethical Studies, College of Social Science and Humanity, Raya University, \\ P.O. Box 92, Maychew, Ethiopia, 2011/2019
}

\begin{abstract}
The objective of this study was to assess the effects of social media on academic performance of female students at Raya University, Ethiopia. It is unclear whether social media use affects positively or negatively the academic performance of female students. The study used both qualitative and quantitative research methodologies and it was based on a descriptive research design. The study targeted second year female students from five colleges registered at the university in academic calendar of 2010/2011. 132 female students were selected trough a proportional stratified sampling technique based on their Grade point Average by categorizing (1.75-2:00, 2.003.00 and 3.00-4.00). The researcher employed both primary and secondary sources and data was collected using questionnaires. The qualitative data was analyzed and interpreted qualitatively using words whereas the quantitative data was analyzed and interpreted through the Excel computer application packages. The results of the study indicated that female students who often accessed social media for academic purpose had higher grade point averages than those who used social media for not academic issues. The study concluded that despite the benefits that female students can harness from social media, there is to some extent addiction and distraction of attention caused by the use of social media which could have serious consequences on the academic life of these students. The researcher therefore recommended that female students of the university should access social media for academic purpose and limit the time they spent on social media site.
\end{abstract}

Keywords: Social Media, Academic Performance, Effects, Students, Raya University

DOI: $10.7176 / \mathrm{NMMC} / 81-02$

Publication date:June $30^{\text {th }} 2019$

\section{CHAPTER ONE: Introduction}

\subsection{Background of the Study}

The advent of the internet in the 1990s led to major developments in the world of communication. In 21 st century the communication is faster, better and efficient the credit goes largely to technology (Dearborn, (2014). Social media networking site facilitates open communication, leading to enhanced information discovery and delivery. This has breached the gab that existed in communication. Today, communication is as easy as walking into a neighbor's residence to deliver a piece of information through the use of social media. Whereby, two-third of the world's population visits social networking sites, thus serving as a communication and connection tool (Andreas and Michael, 2010).

It is known that social media comes with both positive and negative effects. There is a correlation between social media usage and academic performance of students in universities. There are many researches highlighting that the use of social media does not affect female students' academic achievements. For them, female students use social media to discuss their academics issues formally and informally and also to interact with their instructors (Lee, 2010). In addition, Massey (2007) argued that female students are socially connected with one another and therefore share their daily learning experiences and do conversation on various topics through social media. Furthermore, the University of New Hampshire research show that $63 \%$ of heavy users received high grades, compared to $65 \%$ of light users (Gray, 2011). On the other hand, Shankar (2010) reviewed that social media grabs female students' attention and then diverts towards non-educational and inappropriate actions including useless chatting. Moreover, some studies concluded that social media affect the academic achievement of female students because they don't want to leave that particular aura and thus their concentration stands divided.

Studies have not been conducted so far on the effect of social media on the academic achievement of female students in higher education in Ethiopia. As a country, improving the academic achievement of female students are the major issues and all the efforts and resources are engaged in to it. Government, non-government organizations and international partners all are giving their utmost effort to improving the academic achievement of female students and to assure quality of education. But, the effect of using social media on the academic achievement of university students, especially female students is on the bottom of their priority list. That's why there is no information and studies on the effect of using social media on academic achievement of university students in this country.

In the case of Raya University, there is no readily available empirical study to determine the effects of social media on academic performance of female students. Thus, it is unclear whether social media affects negatively or positively the academic performance of female students. This study therefore sought to assess the effects of social 
media on academic performance of female students at the University.

\subsection{Statement of the problem}

The world today is a global market in which the internet is the most important sort of information. Social media have brought both good and bad effects to female students. It has helped many female students to acquire knowledge from one another over internet without necessarily have to meet physically (Wheeler, 2009). It enabled female students to be better informed, enlightened, and keeping abreast with their daily educational life and world developments. Technology exposes female students to a better way of doing academic experiences. On the other hand, since the advent of social media sites in the 1990s, it is assumed in that the academic performance of female students is facing a lot of challenges. For example, a study conducted by Khan (2010) noted that the educational system in Nigeria is faced with so many challenges which have certainly brought about a rapidly decline in the quality of education due to social media. There is a deviation, distraction and divided attention between social networking activities and female students' academic work. It has been observed that female students devote more attention and time to social media than they do for their studies and they cannot pass their examinations well if they do not learn and study (Maya, 2015). For instance, many female students have lost their interest in their studies as they spend most of the time on these sites.

Although minimal researchers have previously examined the impact of social media on academic performance of student in general, they have failed to target females in higher learning institute in Ethiopia. Today, despite the fact that female students at Raya University have been engaged in the use of social media, it is unclear whether social media use affects positively or negatively their academic achievements at the University. The issue has to be more researched and as per the researcher's observation, no research was conducted to assess the effects of social media on academic performance of female students in the case of Raya University. Therefore, this study was conducted to assess the level of engagement of female students of Raya University into social media and also determine the effect of their use on their academic performance.

\subsection{Objectives of the Study}

\subsubsection{General Objectives of the Study}

The general objective of this study was to assess the effects of social media on academic performance of female students at Raya University.

\subsubsection{Specific Objectives of the Study}

1. To identify the level of female students exposure to social media sites at Raya University

2. To assess for what purposes did female students of Raya University use social media

3. To determine how the use of social media has influenced the academic performance of female students of Raya University

\subsection{Research Questions}

1. To what extents are female students of Raya University exposed to social media network?

2. For what purposes did female students of Raya University use social media sites?

3. How has the use of social media influenced the academic performance of female students at Raya University?

\section{Chapter Two: Literature Review}

\subsection{The concept of social media}

Social media means a group of internet- based applications that employs mobile and web based technology to create highly interactive platforms via which individuals and community share, co-create, discuss and modifies user-generated content (Selwyn, 2012). Social media refers to the means of interaction among people in which they create, share, exchange and comment among themselves in different networks. Andreas and Michael (2010) highlighted that social media is a group of internet based application that builds on the ideological foundation and allows the creation and exchange of users generated content. Another definition of social media is that it is a "'communication channel which is very popular, extremely fast and broad, has proven to be highly effective, as well as trusted by billions of people, to share and discover content concerning individuals, brands, information, entertainment and knowhow" (Dearborn, 2014). One theme that all these definitions underpin is that social media involves some form of communication between individuals over the internet.

Today, social media has taken a new dimension and has encouraged more participation through the introduction of mobile phones that support social networks applications. The use of mobile phones that are powered by Android applications to social network is termed as Mobile social networking. According to Dearborn (2014), in his study titled "Mobile Social Networks and Social Practices" social network applications have now been migrated from the computer to the mobile phone, network information and communication can be integrated into the public space; and these new services that are developed for mobile phones allow users to create, develop, 
and strengthen their social ties.

\subsection{Female students' addictiveness to social media}

On the internet, female students engage in a variety of activities some of which may be potentially addictive. The mass appeal of social media on the internet could be a cause for concern, particularly when attending to the gradually increasing amount of time female students spend online. Many female students cannot go for two-three hours without checking and updating their profiles on these social networks even at the detriment of other activities such as educational and career pursuit. Boyd and Esteban (2010) explain social media addiction as the excessive use of the internet and the failure to control this usage which seriously harms female students' academic life.

In an article on the Daily Trust newspaper, Shankar (2010) posits that there seem to be an alarming rate of social networking obsession among students today; a trend that could affect their academic, social and spiritual lives negatively if not properly controlled. Many concerned parents have expressed grave concern that they could hardly get the attention of their children and wards, as they seem to have been carried away by the fascinating world of social networks. Khan (2010) of the Sunday Observer observes that if the dangerous trend of social media network "obsession" if left unchecked could further affect an already collapsing education system in Nigeria. The reason female students are performing poorly in school these days might not be farfetched. While poor quality of lecturers can quickly take the blame, one might think harder if the phrase "Facebook frenzy" has not been heard of. It is a common sight to see a youth chatting in sensitive and highly organized places like church, mosque and lecture venues. Some are so carried away that even as they are walking along the high way, they keep chatting. Attention has been shifted from visible to invisible friends, while important ventures like study and writing are affected in the process. Jain (2005) noted that internet addiction is significantly and negatively related to students' academic performance, as well as emotional attributes.

In a study of 884 students of different universities in Nigeria, Kaplan and Shankar (2010) indicated that students in Nigeria are spending too much time on social networking sites at the detriment of other necessary things such as their studies. They explained that Youths' use of these social networking sites even point towards obsession. The youths have made the social media their top priority and continued to need more usage in order to feel satisfied.

In Boyd and Esteban (2010), a study on Facebook and Academic Performance in Nigeria Universities was carried out on 122 university students; they tested six hypotheses to know the effect of Facebook on the academic performance of students in selected universities. The study tested among other hypotheses that the more time a student spends on Facebook, the lower his or her grade point average will be. Madge (2009) mentioned that among various social networking sites, Facebook remains a major distraction of current generation.

In Selwyn (2012), the author observed that the bone of contention of the social media is the obsessive attitude of Nigerian youths towards its use. He pointed out that students waste their time through idle chats and other immoral acts. Students are so engrossed in the social media networks that they are almost 24 hours online. Even in classrooms and lecture theatres, it has been observed that some students are always busy pinging, 2going or Face booking, while lectures are on. The result is that quality time that ought to be spent on academic research and other productive networking is lost.

\subsection{Female students' exposure to social media}

It has been observed in recent times that female students have unlimited access to the internet as well as the social media (Shankar, 2010). Students connect with computer to send and receive information anywhere on the globe. The manufacturing and distribution of equally sophisticated cellular phones has complicated the situation, as students no longer need to visit a cybercafé before they send and receive messages. Some schools are so equipped that there is internet connection made available within the school premises as well as in the library. Online Wikipedia and blogs are the main resource centers for students as attention have been shifted from making research in the library to overall dependence on theses social platforms. It is a common thing to see a student reading in the library and putting the books aside on hearing the sound of a ping on the phone.

\subsection{Positive effects of social media on students' academic life}

Female students' academic life has moved to a different dimension since the introduction of these social media networks. Several studies conducted by Lee (2010), Gray and Massey (2007) have affirmed that social media plays an important role on female students academic work in higher education. In their study, they recognized four (4) major advantages of social media usage by female students in higher education which included; enhancing relationship, improving learning motivation, offering personalized course material, and developing collaborative abilities. Indeed, social media has contributed greatly to facilitating learning in the 21 st century. It is shown that a greater percentage of female students including those at the $\mathrm{PhD}$ level commonly use social media to ameliorate their studies (Gray, 2011).

The answers to the causes of flexible studies today across the globe might not be far-fetched from the great 
contribution that social media platforms are providing when used judiciously. Even though, the studies conducted by Shankar (2010), argued that social networks distracts the attention and concentration of female students toward learning and converts it towards non educational activities such as useless and unnecessary chatting, there have been several studies conducted afterwards whose findings are contrary to this claim. For instance, the study conducted by Massey (2007), titled "the impact of social networking in promoting education" revealed that students benefit from chatting with other students, teachers and external sources to acquire knowledge. Also, female students gained more vocabulary, improved their writing skills and reduced their spelling mistakes through social media usage. Other scholars; Andreas and Michael(2010), in their study also revealed that social media benefits female students by connecting them to one another on assignments and class projects.

It is further buttressed in the study of Gray (2011) and Lee (2010) whose conclusions were that social media undoubtedly generate new opportunities to engage female students in higher education as they are remarkably effective at connecting people and facilitating the exchange of information. It is clear and indisputable from these studies that social media usage in the educational sector cannot be underestimated since its introduction.

\subsection{Negative effects of social media on female students' academic life}

Shankar (2010) enumerated some of the risks associated with social media which included criminal activities such as identity theft and fake contacts which are prevalent today, sexual abuse or harassment and unsuitable advertising. On the same subject, Tokunaga (2010) also mentioned cyber bullying, online harassment, sexting, face book depression, and privacy concerns as some of the challenges associated with social media usages.

Cyber bullying: cyber bullying is a category of bullying that occurs in the digital realm or medium of electronic text. It is any behavior performed through electronic or digital media by individuals or groups that repeatedly communicates hostile or aggressive messages intended to inflict harm or discomfort on others (Tokunaga, 2010). Privacy concerns: this is another concern that everyone involved in social networking is faced with. The rate at which people post or share fake information calls for alarm and it is difficult to ascertain that, what people say and post are truly who they are. Individuals' private information is publicly displayed on some of these social networks and malicious people take advantage and perpetrate all kinds of harassment (Shankar (2010).

Aside these effects, other studies conducted by scholars have also proved that social media can be detrimental to female students' academic life if caution is not taken in its usage. For instance, the study conducted by Khan (2010) titled "The need for safety consciousness among Youths on social Networking Sites" concluded that social media affects students use of English. They use short-handwriting when chatting with friends and unconsciously get used to it thereby replicating same errors during examinations. Indeed, a number of studies carried out by Maya (2015) have revealed unequivocally that social media can be problematic to female students' academic life if caution is not taken in its usage.

\subsection{Social Media and Ethiopian Higher Education}

The Ethiopian Higher education has felt its own taste of social media since its introduction. Social media in Ethiopia started as a slow process like other African countries but has grown steadily over the past years. According to the Ethiopian National Communication Authority (2017) report, the total mobile subscriptions as well as mobile data subscribers in the country have increased dramatically. This indirectly means there is more access to the internet which of course includes social networking sites. Some studies revealed that majority of female students in Ethiopia were engrossed in social networking sites. It also brought to light that most users utilized these sites for chatting and downloading purposes only which affected their academic performance negatively. This finding corroborates the revelation of Mingle and Charles (2015), that most respondents in their study experienced negative effects such as poor grammar spelling, late submission of assignments, less study time and poor academic performance. Though part of these studies affirmed some benefits of social media usage in the academic life of female students, it is necessary as educators to be concerned about its negative effects which seem to be outweighing the advantages as far as education is concerned in Ethiopia.

\section{Research Methodology}

In this study, both qualitative and quantitative research methodologies were used. Qualitative research methodology is designed to help researchers understand peoples' attitudes, experiences and feelings whereas quantitative research methodology is a systematic investigation of scientific mathematical properties and their relationships. Combining the two methods is helpful to reinforces each other and to come up with well validated and substantial findings.

This study was conducted based on a descriptive research design. This design enables the researcher to generate data through the standardized collection procedures based on almost structured research instrument and well defined study concepts and related variables. By using this method, the researcher was going to describe the existing impact of social media on female students' academic performance at Raya University.

In this study, the researcher employed both primary and secondary sources of data. Thus, the primary data or 
first-hand information was collected using questionnaires from the study area. In addition, since relying only on primary data cannot fully capture current realities, the use of secondary sources of data was imperative. Hence, the data that has obtained from primary sources was supported by the secondary sources. To this effect, literatures and documents was used as secondary sources of data.

Target population according to Kruger and Davies (2012) is the complete set of individuals with some common characteristics to which the research wants to generalize the results of the study. Therefore, this study targeted second year female students from five colleges registered at the university in academic calendar of 2010/2011. Fresh man students were excluded from this study since they have no GPA during the study period.

The study used a proportional stratified sampling technique because according to Mugenda (2008), this method helps the researcher to proportionally represent each sub-group within the sample since every unit has an equal chance of participating in the study and then enables to get more reliable data from each stratum.

In this study, of the total 900 students, the researcher selected 30\% (132) female students based on their Grade Point Average (GPA) by categorizing (1.75-2:00, 2.00-3.00 and 3.00-4.00) from all colleges. The study therefore sampled 132 female students representing $30 \%$ of the total target population. This is because the greater the sample size, the smaller the sampling error and the more representative the sample becomes. A sample of $30 \%$ is a good representative of the target population and hence adequate for analysis (Mugenda, 2008). After deciding this sample size, the researcher distributed 132 copies of questionnaires to 132 female students' respondents and retrieved on the spot by the researcher. Hence, all the respondents filled and retuned the questionnaires making a response rate of 100\%. According to Wheeler (2007), a response rate of 50\% and above is adequate for analysis and can be used to represent the opinion of the entire population. Thus, in this study, $100 \%$ of a response rate is even the best.

Pre data collection orientation with sample research questions was given to the respondents so as to adjust necessary concepts and to review the difficulties which could be faced during the data collection process in the actual study. The questionnaires was hand delivered (distributed) and then collected by the researcher himself. Moreover, during the data collection process, the researcher made clarifications in case of unclear issues to the respondents. A self-administered questionnaire is desirable because of low cost and a large number of respondents may be reached.

The researcher collected the needed data through the use of questionnaire because according to Stafan (2016), questionnaires allow respondents to respond questions confidentially and independently without any interference so as to minimize biases because of the presence of other persons. In addition, questionnaire provide a relatively cheap, quick, and efficient way of obtaining large amount of information from sample respondents and was useful for large populations when interview would be impractical. In this study, the researcher used both closed and open ended questionnaires together in order to obtain adequate quantitative and qualitative data as well as to fill the gap that was missed (not touched) by either closed or open ended questions.

Finally, following the completion of data collection, the data have been edited and structured for analysis and interpretation purposes. In the end, the qualitative data was analyzed and interpreted qualitatively using words whereas the quantitative data was analyzed and interpreted through the Excel computer application packages. The results were then presented using frequency and percentages distribution, tables and charts.

\section{Data Presentation and Analysis}

\subsection{Analysis of Research Questions}

Figure 1: The level of female students' addiction to social media

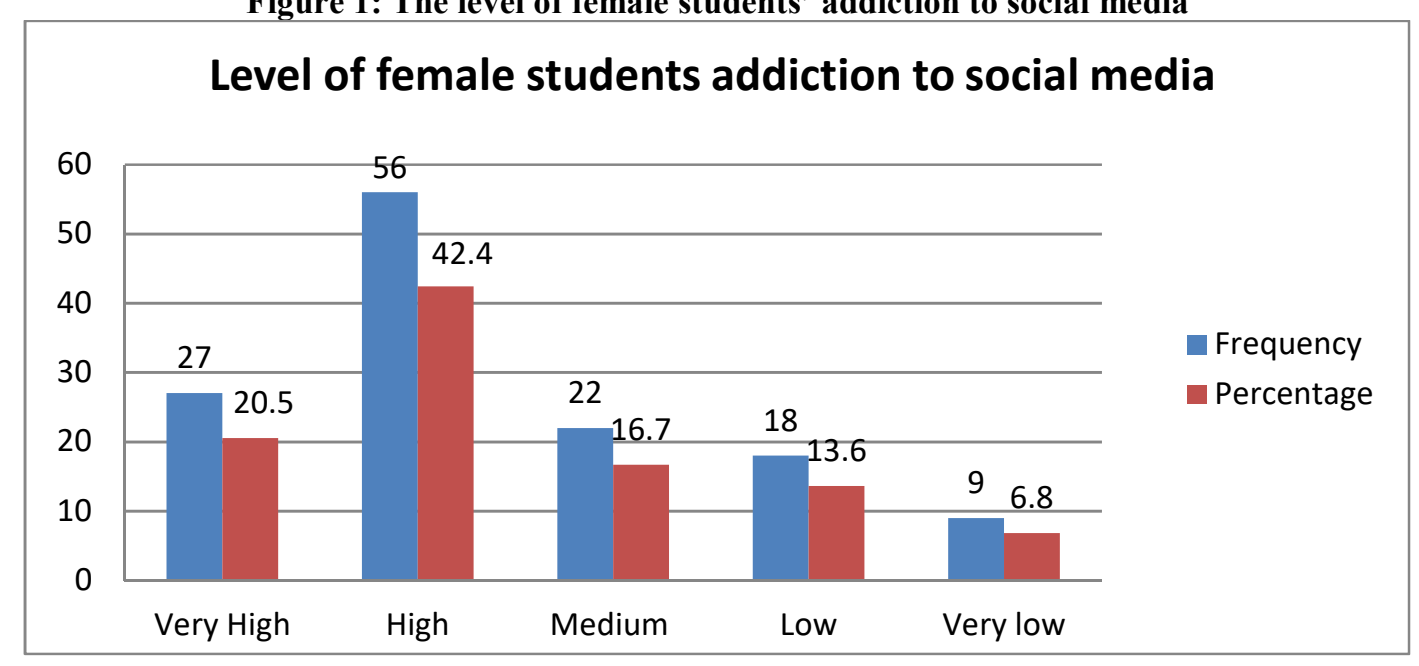

Source: Computed from own survey data (2018) 
As depicted in figure 1 above, the respondents were asked to rate the level of female students addiction to social media in the study area. Accordingly, the result shows that while $18(13.6 \%)$ and $9(6.8 \%)$ rated as low and very low respectively, 22(16.7\%) rated their addiction as medium. However, the majority $56(42.4 \%)$ have labeled their addiction to social media as high while the rest rated it as very high. In support of this idea, Boyd and Esteban (2010) explained social media addiction as the excessive use of the internet and the failure to control this usage which seriously harms female students' academic life.

Figure 2: The social networking site mainly used by female students at Raya University

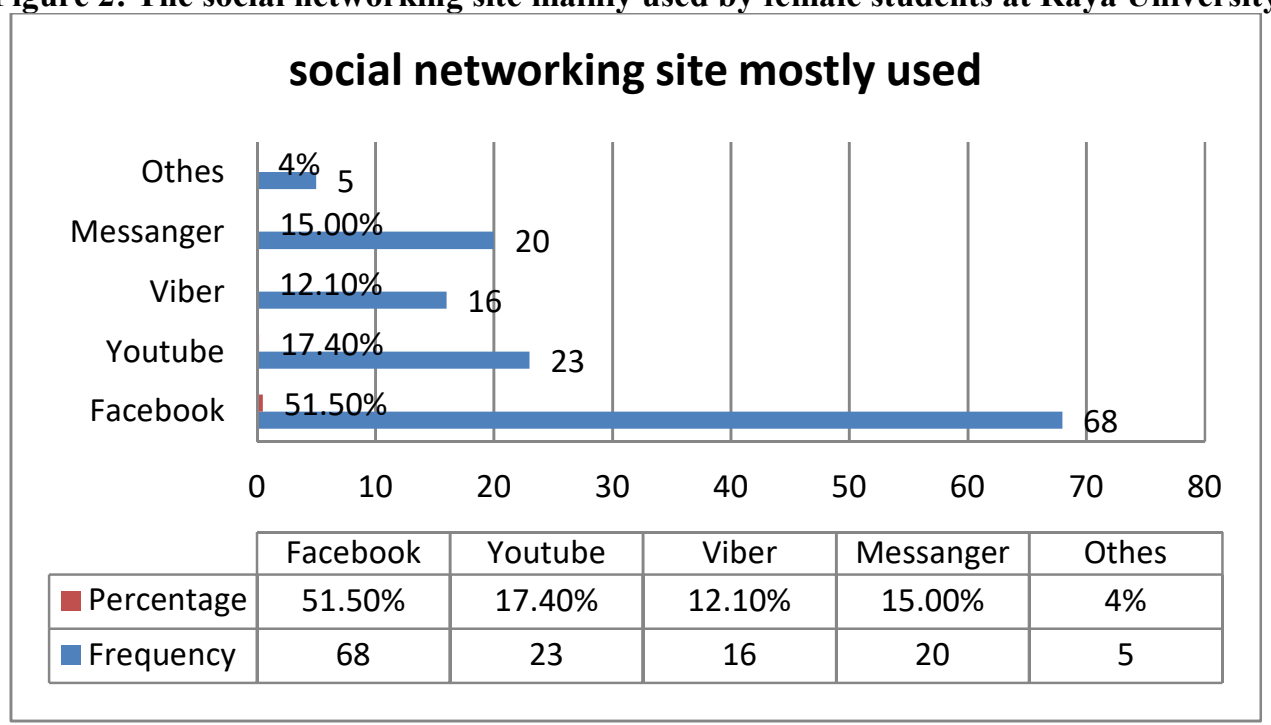

Source: Computed from own survey data (2018)

As figure 2 above shows, from a sample of 132 female students the researcher found that all the students used various social networking sites. However, though most of the female students (51.5\%) at Raya University mainly used Facebook, they also used different social networking sites like YouTube, viber, and messenger for various purposes. They also used Twitter, Skype \&What Sapp. In support of this idea, Madge (2009) mentioned that among various social networking sites, Facebook remains a major distraction of current generation. In addition, a study carried out on 122 Nigerian university students by Boyd and Esteban (2010), tested that the more time a female student spends on Facebook, the lower their grade point average will be.

Figure 3: For what purposes female students mainly used social media network sites

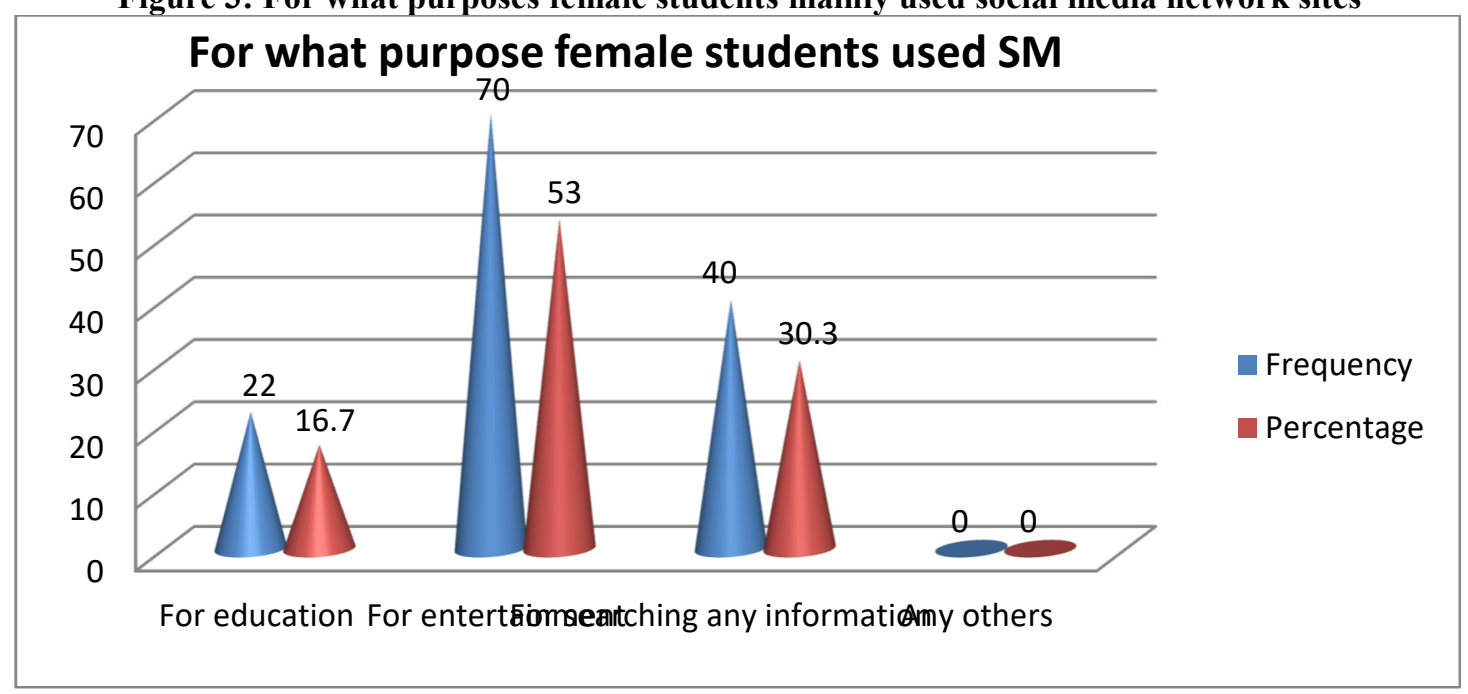

Source: Own survey data (2018)

In figure 3 above, the respondents were asked for what purposes female students mainly used social media network sites in the study area. As a result, they were able to point out the different purposes for which they used social media network sites. The highest score (53\%) of the respondents revealed that female students used social media for entertainment/ downloading music, chatting, posting photos and searching for new friends/ followed by $30.3 \%$ for searching any information. Only $16.7 \%$ is used for educational purposes such as searching for assignment/quizzes and communication with class fellows. 
Table 3: Female student's exposure to social media and their academic performance

\begin{tabular}{|c|c|c|c|c|c|}
\hline \multirow[t]{2}{*}{ No } & \multirow[t]{2}{*}{ Statement } & \multirow[t]{2}{*}{ Value } & \multicolumn{3}{|c|}{ Responses } \\
\hline & & & Yes & No & Total \\
\hline \multirow[t]{2}{*}{1} & \multirow{2}{*}{$\begin{array}{l}\text { Female student's exposure to social media network } \\
\text { has significant influence on their academic } \\
\text { performance }\end{array}$} & $\mathrm{F}$ & 82 & 50 & 132 \\
\hline & & $\%$ & $62.1 \%$ & $37.9 \%$ & $100 \%$ \\
\hline
\end{tabular}

Source: Own survey data (2018)

As shown in table 3 above, respondents were asked whether female student's exposure to social media network has significant influence on their academic performance or not. Accordingly, the majority (62.1\%) of the respondents replied that their exposure to social media network has significant influence on their academic performance because female students were not effective at using social networking sites for academic purposes. They would not perform well in their academics as if they have unlimited access in using social media. On the contrary, $37.9 \%$ of the respondents indicated that social media sites fostered female students' academic achievements since they rely on information gotten from social media networking site like Wikipedia, to do their assignments without consulting other sources. They used materials gotten from blogging sites to complement what they have been taught in the class.

Figure 6: The trends of social media usage by female students in Raya University between the years 20102011 E.C

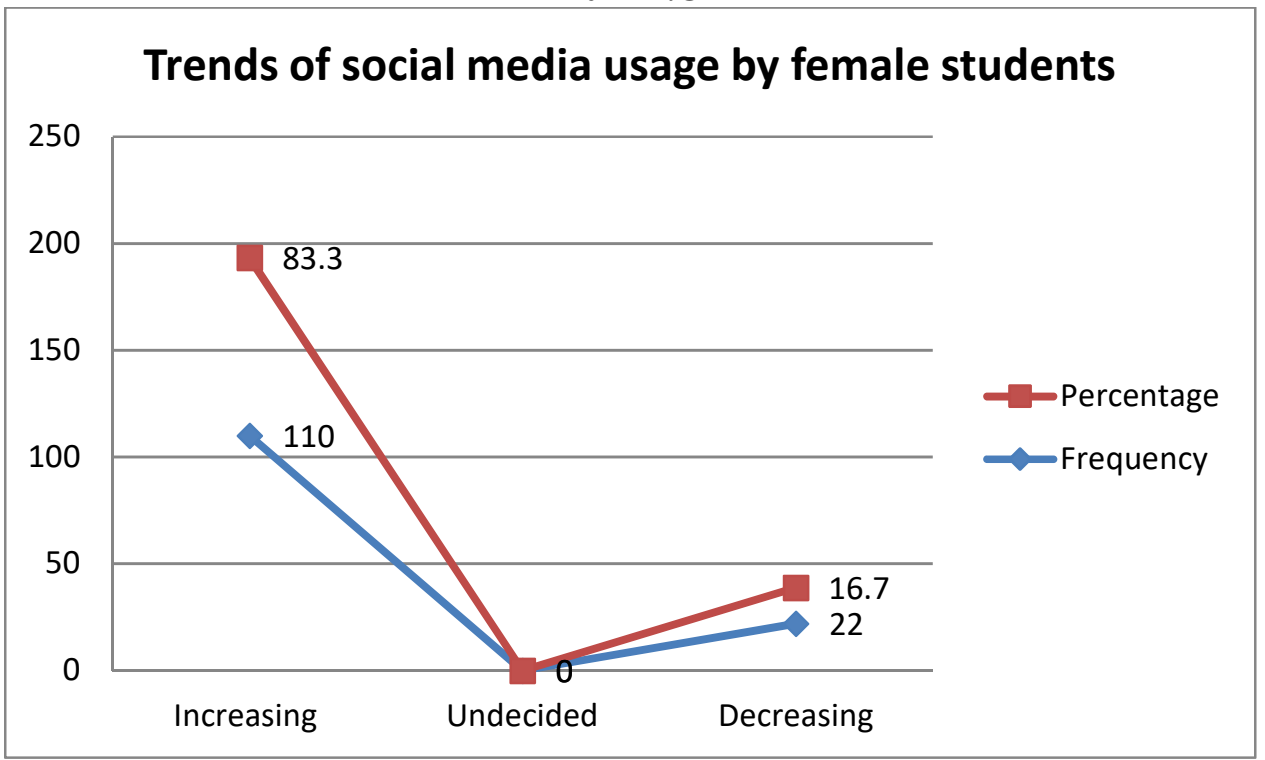

Source: Own survey data (2018)

Concerning the trends of social media usage by female students at Raya University between the years 20102011 E.C., (16.7\%) rated the trend as decreasing from time to time while the majority $(83.3 \%)$ of the respondents indicated the trends of social media usage as increasing in an alarming rate in the University. For them, this is because the university allowed unrestricted access to internet sites and using social media by Raya University female students is becoming certainly a fashion as portion of their daily life. Concomitant to this idea, Shankar (2010) pointed out that there seem to be an alarming rate of social networking obsession among female students today; a trend that could affect their academic lives negatively if not properly controlled. 
Figure 7: The effects of social media on the academic performance of female students

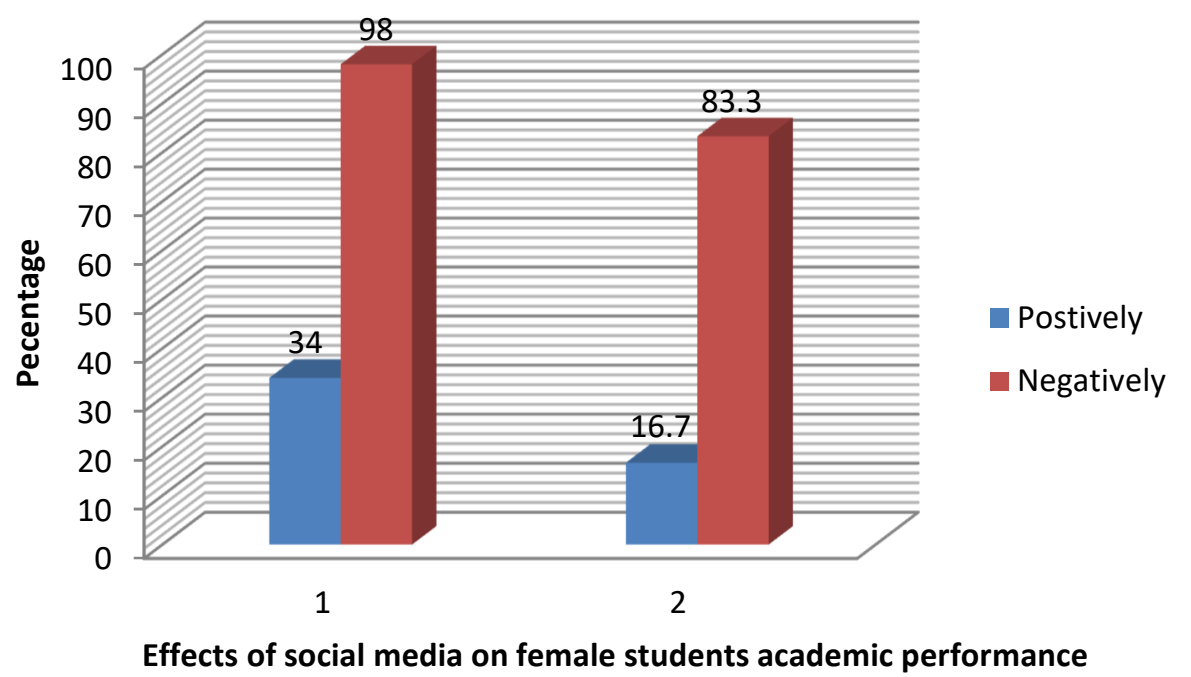

Source: Own survey data (2018)

In the above figure, the female students were asked to identify the effects of social media on their academic performance at Raya University. Accordingly, the result shows that $34(16.7 \%)$ of the respondents reported that using social media has positive impact on their academic performance while a significant majority $98(83.3 \%)$ has outlined that using social media has negative impact on their academic performance (fig.7). Most of the respondents replied that using social media negatively affected the academic performance of female students at Raya University. This is because online social networks distract them from their studies and used it for nonacademic purpose with no time limitation. The hours spent on social media, due to the failure to control this usage, can never be compared to the number of hours they spent on studying and reading. Moreover, according to the respondents, female students usually have unlimited access to Facebook and this has affected negatively their academic performance. Besides, Jain (2005) noted that social Media addiction is significantly and negatively related to female students' academic performance.

\section{Conclusion and Recommendations}

\subsection{Conclusion}

The study was conducted to examine the effects of social media on female students' academic performance at Raya University. As a result, the study revealed that most of female students $(42.4 \%)$ at Raya University were highly addicted users of social media which ultimately leads to their poor academic performance. The study show that more than half female students $(51.5 \%)$ at Raya University used Facebook for various purposes. From the findings of this study, it is possible to conclude that majority (53\%) of female students at Raya University have used social media for entertainment purpose rather than for their academic better. Depending on the findings, the researcher concluded that most female students $(45.5 \%)$ have made social media their top priority and hence spent between 2-3 hours per day. Hours spent online can never be compared to the number of hours they spent reading. The study also indicated that most female students (38.6\%) were exposed to social media network/ have unlimited access to social media/ at high level plus the majority $(62.1 \%)$ of the respondents replied that their exposure to social media in turn negatively influenced their academic achievements. The study concluded that the trends of social media usage by female students have been increasing in an alarming rate in the University. Concomitant to this idea, the study discovered that the use of social media has affected the academic performance of female students negatively. Finally, the study revealed that female students are performing poorly in their academic achievements at Raya University these days due to social media.

\subsection{Recommendation}

Based on the findings, the researcher recommended that:

1. Seminars should be organized in various colleges in order to enlighten and informed female students more about the possible implications of social media usage on their academic performance.

2. Female students of the university should think more about the balancing equation of social media usage and their academics

3. Students should better manage their study time and prevent distractions that can be provided by the social 
media. Students must minimize the time they spend on social media to avoid being obsessed by these sites for unnecessary chatting.

4. The use of Social media network by students should focus on the academic relevance of those sites instead of using them for negative purposes.

5. The University instructors should encourage female students on using social sites for academic purpose/ online discussion on assignment, online paper submission and online evaluation or SIMS)

6. The university authority should also restrict access to certain social media sites that may be prone of distracting students' attention during school hours as a means of minimizing their use.

\section{References}

Andreas, M., Michael, H. (2010). The Challenges and Opportunities of Social Media. New York: Macmillan Boyd, D. \& Esteban, R. (2010). Predicting the Future with Social Media. Newbury Park, California: Sage Dearborn, E. (2014). My Official Definition of Social Media. Prospect Heights, Ill: Waveland.

Gay, L. (2011). Educational Research, New York: Mac millan Publishing Company.

Jain, N. (2005). The Effect of Internet Addiction. Korean Journal of Yeolin Education. Vol 5 (3). Khan, S. (2010). Impact of Social Networking Websites on Students Grades. Belmont, CA: Wadsworth. Kruger, J., \& Davies, T. (2012). Research Methodology: Cape Town: Thomson International.

Kaplan, A.M. \& Shankar, P. (2010). The Impact of Social Networking on Education. London: Longma. Leedy, D., \& Ormrod, J. E. (2005). Practical Research (8th ed.). Upper Saddle River, NJ: Pearson.

Lee, A. (2010). Facebook and Academic Performance. Computers in Human Behaviors, (26) pp. 1237-1245. Madge, K. (2009). The Effectiveness of Facebook on students' perceptions.Cambridge University Press. Massey, E. (2007). The Role of Social Networks in Students' Learning Experiences. ACM Bull 39(4), 24-37. Maya, P. (2015). Social Media and Academic Performance of Students. Press Thousand Oaks, CA: Sage. Mingle J., \& Charles, S. (2015). Social Media and Academic Performance in Ghana. Monsey, NY: Willan. Mugenda, A. G. (2008). Research Methods: Quantitative and Qualitative Approaches. Nairobi: Acts Press. Selwyn, N. (2012). Social Media and Nigeria Youth Burden. Johnson \& Wales University.

Rifkin, G. \& Leach, B. (2009). Educating the Net Generation. Carlifornia, USA: Creative Commons. Selwyn, N. (2007). The Use of Computer Technology in University Teaching \& Learning. Cape Town: Juta. Shankar, P. (2010). The Impact of Social Networking Usage on Grades among College Students. ASBBS. Tokunaga, R. (2010). A Critical Review on Cyber Bullying Victimization. Pretoria: Government Press. Wheeler, A. (2007). Educational Research (3rd ed.). Chicago: University of Chicago Press. 